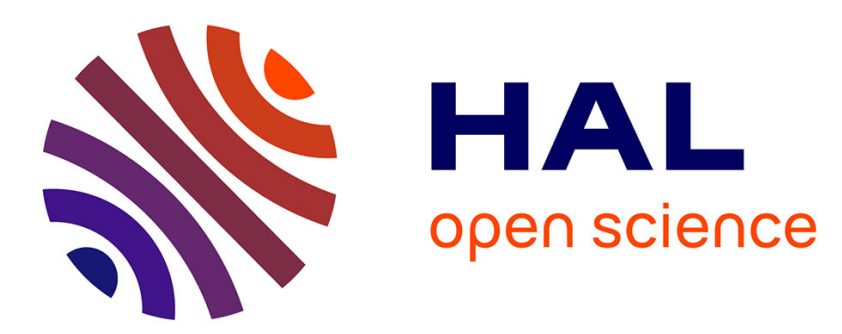

\title{
Litter leachates have stronger impact than leaf litter on Folsomia candida fitness
}

\author{
Mathilde Chomel, Virginie Baldy, Marie Guittonny, Stephane Greff, Annie
} Desrochers

\section{- To cite this version:}

Mathilde Chomel, Virginie Baldy, Marie Guittonny, Stephane Greff, Annie Desrochers. Litter leachates have stronger impact than leaf litter on Folsomia candida fitness. Soil Biology and Biochemistry, 2020, 147, pp.107850. 10.1016/j.soilbio.2020.107850 . hal-02571920

\section{HAL Id: hal-02571920 https://hal-amu.archives-ouvertes.fr/hal-02571920}

Submitted on 11 Dec 2020

HAL is a multi-disciplinary open access archive for the deposit and dissemination of scientific research documents, whether they are published or not. The documents may come from teaching and research institutions in France or abroad, or from public or private research centers.
L'archive ouverte pluridisciplinaire HAL, est destinée au dépôt et à la diffusion de documents scientifiques de niveau recherche, publiés ou non, émanant des établissements d'enseignement et de recherche français ou étrangers, des laboratoires publics ou privés. 


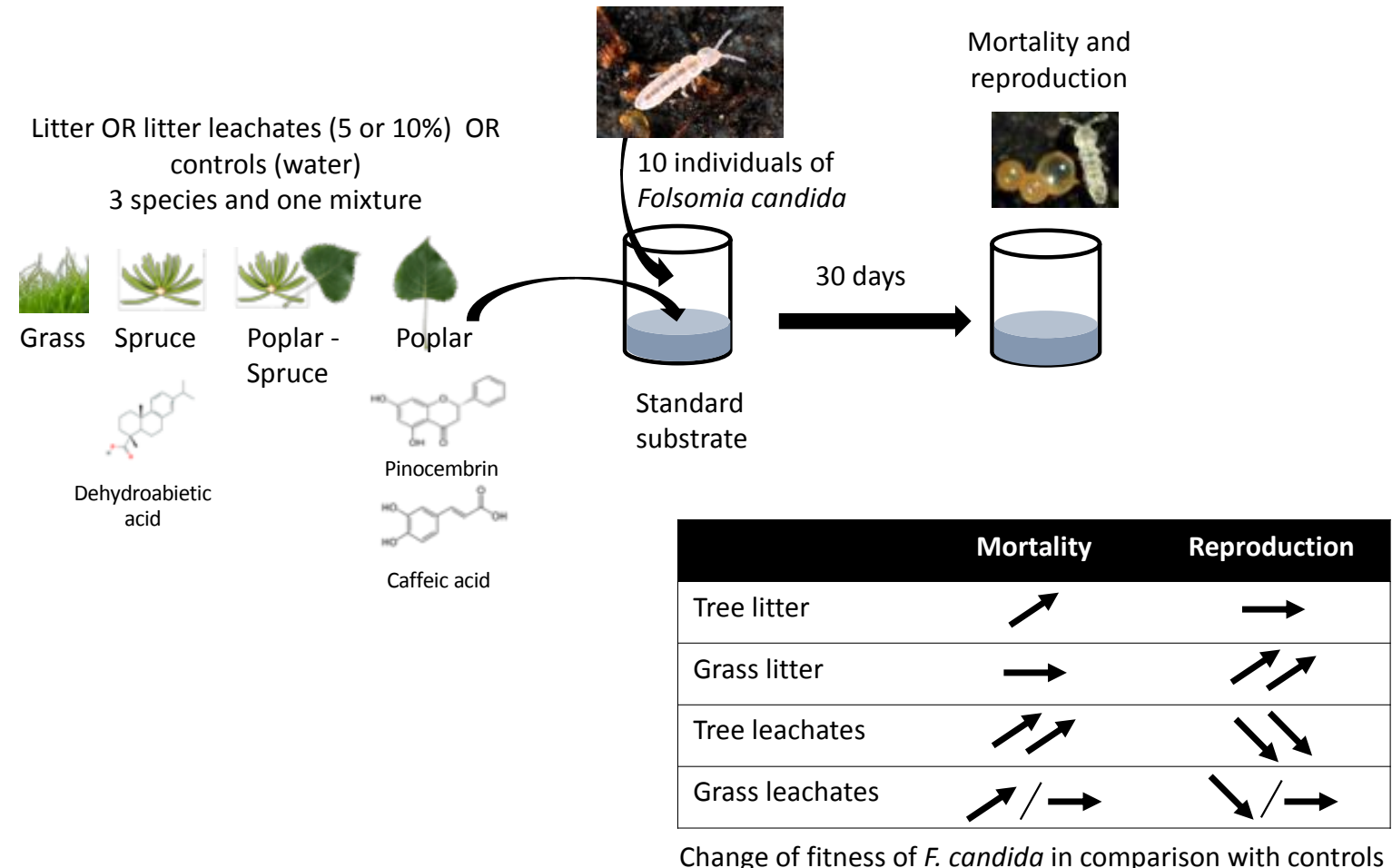

Tree litter leachates increased mortality of Folsomia candida in comparison with the litter treatment or the controls, probably due to the solubility of secondary metabolites contained in the leaves and released in a free form in leachates. 


\section{Highlights}

- Tree litter leachates have stronger influence than litter itself on Folsomia candida fitness

- Tree litter leachates have stronger effect on F. candida fitness than grass litter due to their content in secondary metabolites

- Soluble phenolic compounds released by litter leaching can drive $F$. candida fitness

- Litter compounds leaching appears to be an important process in abovegroundbelowground interactions 
$4{ }^{a}$ Department of Earth and Environmental Sciences, University of Manchester, Oxford Road,

5 Manchester M13 9PT, UK. (present address of the corresponding author)

6 b Institut Méditerranéen de Biodiversité et d'Ecologie - Aix Marseille Université, CNRS, IRD,

7 Avignon Université, IMBE UMR 7263, 13331 Marseille Cedex 03, France

$8{ }^{c}$ Université du Québec en Abitibi-Témiscamingue - Institut de recherche en mines et en

9 environnement, 445, boul. de l’Université, Rouyn-Noranda, Québec J9X 5E4, Canada.

$10{ }^{\mathrm{d}}$ Université du Québec en Abitibi-Témiscamingue - Institut de Recherche sur les forêts, 341

11 rue principale Nord, Amos, Québec J9T 2L8, Canada.

12

$13 *$ Corresponding author.

14 Email address: mathilde.chomel@manchester.ac.uk

15 Key words: secondary metabolites; dissolved organic compound; Collembola; mortality;

16 reproduction; metabolomic 
It is well known that soil physico-chemical conditions and the nature of organic matter have important effects on soil micro-arthropod communities, including collembolans. However, mechanisms by which the physical or chemical quality of litter influence collembolan communities remain unclear. Plant secondary metabolites are partially released in soils through leaf and litter leaching and decomposition, and can have a strong influence on soil communities and their activity. In order to disentangle effects of the water-soluble compounds contained in the litter versus its physical effect, a microcosm experiment was set up exposing the collembola species Folsomia candida to either litter or litter leachates mixed to the substratum. Litter from three species with different chemical properties and one mixture (hybrid poplar, white spruce, grass and a mixture of poplar - spruce litter) and two concentrations of litter leachates (at $5 \%$ and $10 \%$ concentration) were used in microcosm experiments. After 30 days of incubation, reproduction and mortality rates of $F$. candida were assessed. Results showed that the tree litter leachates had a stronger impact on collembolan fitness compared to the litter itself, with a net reduction of survival and reproduction rates. Between 78 and $100 \%$ of mortality was observed in microcosms that received tree leachates, indicating a strong influence of the soluble compounds contained in tree leaves on collembolan. In contrast, collembolan reproduction was positively affected by the grass litter or $10 \%$ grass litter leachates compared to control (water). Our findings help to understand how chemical properties and leaf leaching may have important impacts on micro-arthropods communities and litter decomposition processes.

\section{Introduction}

Physical and chemical characteristics of plant leaves exert an important control on litter

41 decomposition processes, mainly through their impact on the activity of litter-feeding 
invertebrates and microorganisms. For example, previous food choice experiments showed that earthworms or isopods were sensitive to the quality of the litter (Hättenschwiler and Bretscher, 2001; Joy and Joy, 1991; Rief et al., 2012). During the first stages of leaf litter decomposition, an important amount of soluble compounds is lost through leaching, representing up to $30 \%$ of total leaf litter carbon, and released into the soil (Berg and McClaugherty, 2008). These water-soluble compounds are in a great proportion labile and readily available, and are an important nutrient source for decomposers and microbial communities (Joly et al., 2016; Marschner and Kalbitz, 2003). However, secondary metabolites can also be leached out from green foliage and decomposing litter, and released into the soil (Gallet and Pellissier, 1997; Rice, 1984). These compounds are defense compounds to prevent herbivory or parasitism (i.e. terpenes and phenolic compounds), or to resist against inter- and intraspecific competition in allelopathic mechanisms (Chomel et al., 2016; Fernandez et al., 2013, 2006). Once released in the environment through leaching or litter decomposition they are in a free form that may resist degradation and can have strong impacts on the growth and activity of decomposers, from macro-arthropods to microorganisms (Chomel et al., 2016; Hättenschwiler and Vitousek, 2000; Kuiters, 1990). Some studies showed that microbial activity is highly responsive to litter leachates input with a change in the soil microbial community (Cleveland et al., 2007; Joly et al., 2016; Wieder et al., 2008). However, little is known about their effect on soil fauna communities.

Collembolans are important members of the soil decomposer food web and have important direct or indirect roles on the decomposition process (Petersen and Luxton, 1982). Some species are microbivores and stimulate or regulate litter fungal colonization by grazing on the fungal hyphae, while others are detritivores and directly participate to organic matter transformation by fragmenting and ingesting the litter; in both cases they derive nutritional benefits from the decomposing litter source (Das and Joy, 2009). Collembolans are selective 
with their food, and for example they can perceive chemical cues of fungi at a distance of 1 cm - 2.5 cm (Auclerc et al., 2010; Salmon and Ponge, 2001), prefer some fungal species over others (Heděnec et al., 2013; Klironomos et al., 1992; Scheu and Simmerling, 2004), and can suffer a reduction in fitness from the ingestion of specific fungal species (Klironomos et al., 1999; Scheu and Simmerling, 2004). Furthermore, collembolans raised on fungal-colonized litter show grazing preferences and reproduction rates that are more affected by litter type than by fungal species (Heděnec et al., 2013), demonstrating the strong influence of litter quality on collembolans activity (Das and Joy, 2009). However, few studies have addressed the direct impact of the chemical composition of litter on the abundance and diversity of soil mesofauna, the physical structure of the litter often being a confounding factor. Das and Joy (2009) reported that a collembolan species (Cyphoderus javanus Börner) tended to avoid litter with greater amounts of polyphenols and tannins. Furthermore, individuals that remained in contact with litters containing greater quantities of these secondary metabolites exhibited slower growth, lower fecundity and fewer moults (Das and Joy, 2009). Poinsot-Balaguer et al. (1993) found that condensed and hydrolysable tannins extracted from oak leaves were highly toxic for the collembolans (Poinsot-Balaguer et al., 1993). However, these studies related collembolans fitness to the total content of secondary metabolites, but did not consider their solubility in water and their bioavailability in natural environments. Some researchers assert that allelopathic plant-plant interference is most likely due to water-soluble compounds (Vyvyan, 2002). Following the same idea, these water-soluble secondary metabolites leached from the canopy or the litter could be of greater importance for the activity of soil organisms than the litter content itself.

Previous in-situ studies showed that mixing spruce and poplar in plantations could offer valuable ecosystem services, such as tree productivity and soil carbon storage compared to monospecific plantations (Chomel et al., 2014). Mixture of different litter species can enhance 
their respective decomposition rate due to the transfer of nutrient between litter species, the complementarity of diverse resources for the decomposers, or the dilution of secondary metabolites (Gartner and Cardon, 2004; Gessner et al., 2010; Hättenschwiler et al., 2005). Similar positive results were observed for mixtures of leachates, leading to a stimulation of microbial activity (Zheng et al., 2014). In our in-situ studies, although we did not find higher decomposition in a mixture of poplar and spruce litter, some differences with tree species were observed in the mixed plantations and the collembolan abundance was (i) lower under poplar trees than spruce trees (Chomel et al., 2015a), (ii) greater in grass litter compared to poplar or spruce litter (Chomel et al., 2015b), and (iii) increased when grass litter was added to poplar or spruce litterbags. To understand if these patterns were due to the leaf chemistry of the different species, since poplar, spruce and grass litters have different qualities, controlled experiments are necessary. In this study we used the model collembolan species Folsomia candida Willem (Collembola: Isotomidae), which is among the most intensively studied of all species of Collembola (Hopkin, 1997). This parthenogenetic species is widely distributed in many environments, including forests (Fountain and Hopkin, 2005) and is commonly found in the litter layer of coniferous and deciduous forests (Christiansen and Bellinger, 1980), even under the boreal climate of Canada (Skidmore, 1995). Moreover, this species is frequently used in microcosms experiments as it is easy to maintain in laboratory and have a short reproductive cycle (Fountain and Hopkin, 2005).

The aim of this study was to disentangle the effects of litter water-soluble compounds (released by senescent leaves leaching) from the litter itself on the abundance and activity of the Collembola $F$. candida. For this purpose, we compared the effect of three litter species and one mixture (hybrid poplar, white spruce, grass and a mixture of poplar - spruce litter) and their respective leachates on $F$. candida fitness by using the modified ecotoxicological test 'Effects of pollutants on reproduction of Folsomia candida' proposed by the International 
117 Standards Organization (ISO 11267, 1999). During the experiment, $F$. candida were fed with

118 yeast to tease apart nutrient effects associated to the treatments and focus on secondary 119 metabolites effects. We tested the following hypotheses: (i) following results from our in-situ

120 studies (i.e low abundance of collembola under poplar trees and high abundance in grass

121 litter), we expected to find a high concentration of phenolic compounds with allelopathic

122 activities in poplar litter and a low concentration in grass litter; (ii) A gradient of the effect of

123 litter and leachates on the fitness of $F$. candida should be observed in the following order

124 from positive to negative: grass > spruce > poplar; (iii) litter leachates have a more

125 pronounced impact on $F$. candida compared to litter since nutrients and secondary metabolites

126 would be directly bioavailable for collembolans; (iv) litter and leachate diversity from the

127 mixture is expected to stimulate $F$. candida fitness in comparison with monospecific litter and

128 leachates due to complementarity effects induced by mixed species.

129 2. Material and methods

\subsection{Litter sampling and leachates preparation}

131 In late September 2010, three types of senescent leaves (poplar, spruce and grass) were

132 collected from experimental monospecific plantations of hybrid poplar (Populus

133 maximowiczii A. Henry x P. balsamifera L.) and white spruce (Picea glauca [Moench] Voss)

134 located in Amos $\left(48^{\circ} 36^{\prime} \mathrm{N}, 78^{\circ} 04^{\prime} \mathrm{W}\right)$ in the boreal region of Abitibi-Temiscamingue,

135 Quebec, Canada. Freshly fallen spruce needles and hybrid poplar leaves were collected by 136 placing a plastic sheet beneath the trees to prevent soil contamination. Aerial parts of grass

137 species (mainly grasses, i.e. Poa sp.) naturally present in the plantation were cut at ground

138 level during the same period. Collected leaf material was homogenized, air-dried and stored at

139 room temperature prior to the experiment. Leachates of each litter type (poplar, spruce, grass

140 and poplar/spruce [50:50]) were prepared by soaking $100 \mathrm{~g}$ of litter (air-dried mass) in $1 \mathrm{~L}$ of 
141 deionized water (10\% dry mass) for $24 \mathrm{~h}$ in darkness. This concentration is the most

142 commonly used for in vitro allelopathy bioassays (Chen et al., 2013; Fernandez et al., 2013).

143 Although they can be more concentrated than in natural conditions, it allows studying the

144 potential allelopathic effect of a species (Kil, 1992). However, to be more representative to 145 actual field concentrations, a 50\% diluted solution was also prepared, producing 5\% dry mass 146 leachate.

\section{$147 \quad 2.2$ Folsomia candida cultures}

148 A population of a single clone of $F$. candida was reared in plastic boxes containing a mixture 149 of permanently water saturated plaster of Paris and activated charcoal in a ratio 9:1 and 150 maintained at $20^{\circ} \mathrm{C}$ with food (dry yeast pellets) available ad libitum. To synchronize age of 151 the organisms, oviposition was stimulated by imposing a cold period and then placing the 152 adults on a new breeding substrate (Fountain and Hopkin, 2005). After oviposition, adults 153 were removed and eggs hatched 3-4 days later. Individuals became sexually mature 16 days

154 after hatching, and to ensure a homogeneous cohort of juveniles, all the young individuals 155 were placed in a large container and fed for the first time at the same time.

\subsection{Experimental design}

157 To study the effects of litter or leachates on the fitness of $F$. candida, we set up a total of 65 158 microcosms. The microcosms were set-up according to 2 interacting factors: the litter form 159 (litter, 5\% leachate and 10\% leachate) and the litter species (poplar, spruce, grass and poplar 160 spruce mixture) and controls consisted of deionized water without litter. Each combination of 161 factors was replicated five times. The $F$. candida reproduction test was carried out according 162 to an adaptation of the ISO standard 11267 (ISO 11267, 1999). The microcosms consisted of $163120 \mathrm{~mL}$ plastic bottles with pierced screw caps containing $32 \mathrm{~g}$ of wet artificial soil, made up

164 with $70 \%$ quartz sand, $20 \%$ kaolinite and $10 \%$ peat, ground, dried, and sieved to $0.5 \mathrm{~mm}$ with 
165 the $\mathrm{pH}$ adjusted to $6.0 \pm 0.5$ by the addition of $\mathrm{CaCO}_{3}$. It was moistened to $50 \%$ of water

166 holding capacity with distilled water $(7 \mathrm{~mL})$. Chemicals to be tested in the ISO norm are

167 generally pollutants dissolved in water at range of concentrations that will give appropriate

168 reduction of reproduction levels (LOEC, CE 50). For this experiment, $7 \mathrm{~mL}$ of 5 or $10 \%$

169 leachates were directly mixed with the soil. For the litter species treatments, $7 \mathrm{~mL}$ of distilled

170 water were added to the substrate, and $1 \mathrm{~g}$ of coarsely chopped litter was re-humidified and

171 placed on the substrate (corresponding to the amount of litterfall per surface area in natural

172 plantations, Chomel et al. 2014). For each microcosm, ten 10/12-days-old juveniles were

173 introduced and the microcosms were randomly placed in a climate chamber at a constant

174 temperature of $20^{\circ} \mathrm{C}$ and continuous darkness for 30 days. They were opened twice a week for

175 aeration and fed with baker's yeast at the initial time and after 2 weeks. Following the ISO

176 guidelines, the pots were flooded with water and gently stirred to collect and count the

177 animals floating at the surface. The number of surviving adults and the juveniles were

178 recorded using a dissecting microscope.

179

180

181

182

183

184

185

186

187

\subsection{Chemical composition of litter and leachates}

Litter initial content of major nutrients $(\mathrm{C}, \mathrm{N}, \mathrm{P})$ and phenolics were estimated from 5 subsamples of each litter. The litter samples were finely ground with a ball mill (MM301, Retsch Inc., Newtown, PA) prior to analysis. Carbon (C) and Nitrogen (N) concentrations were analysed in a CHN elemental analyzer (Flash EA 1112 series, ThermoScientific, U.S.A.). Phosphorus (P) was extracted with $20 \mathrm{~mL}$ of nitric acid from remaining dry ash after combustion of $0.5 \mathrm{~g}$ of subsamples at $500{ }^{\circ} \mathrm{C}$ for $5 \mathrm{~h}$ in a muffle furnace. The $\mathrm{pH}$ was adjusted to 8.5 with a $40 \% \mathrm{NaOH}$ solution. A volume of $1 \mathrm{~mL}$ of sample, $0.2 \mathrm{~mL}$ of mixed reagent (emetic tartar and ammonium molybdate solution), $0.04 \mathrm{~mL}$ of ascorbic acid and $0.76 \mathrm{~mL}$ of distilled water were placed directly in a microcuvette. After $150 \mathrm{~min}$, the reaction was completed, and phosphorus concentration was measured at $780 \mathrm{~nm}$ with a UV/Vis 
spectrophotometer (Thermo Scientific ${ }^{\circledR}$, USA). Total phenolics content was measured by the

191 method of Folin-Ciocalteu (Folin and Denis, 1915): $1 \mathrm{~g}$ of ground litter was shaken with 20

$192 \mathrm{~mL}$ of distilled water for $90 \mathrm{~min}$. A volume of $0.25 \mathrm{~mL}$ of the filtered aqueous extract (or of

193 the leachate directly) was mixed with $0.25 \mathrm{~mL}$ of Folin-Ciocalteu reagent and $0.5 \mathrm{~mL}$ of

194 saturated aqueous $\mathrm{Na}_{2} \mathrm{CO}_{3}$ to stabilize the colour reaction, after which $4 \mathrm{~mL}$ of distilled water

195 was added to dilute the extract. After 1 hour, the reaction was completed and measured at 765

$196 \mathrm{~nm}$ on a UV/Vis spectrophotometer (Thermoscientific, U.S.A.). Quantitative results were expressed with reference to gallic acid.

\subsection{Litter metabolic fingerprints (untargeted metabolomics)}

The metabolomic profile of the litter was analyzed following the method from Hashoum et al. (2017). A dry mass of $200 \mathrm{mg}$ of sample was suspended in $4 \mathrm{~mL}$ of methanol:water (50:50), and subjected to ultrasonication for $5 \mathrm{~min}$ at room temperature. Extracts were then filtered using a syringe filter (PTFE $13 \mathrm{~mm}, 0.22 \mu \mathrm{m}$, Restek, USA). Analyses were performed with an UHPLC instrument (Dionex Ultimate 3000 equipped with a RS Pump, an autosampler, a

204 thermostated column compartment and a UV diode array, Thermo Scientific ${ }^{\circledR}$, USA) coupled to an accurate mass spectrometer (qToF) equipped with an ESI source (qToF Impact II, Bruker Daltonics ${ }^{\circledR}$, Germany). UHPLC separation was done on an Acclaim C18 column (150 $207 \mathrm{~mm} \times 2.1 \mathrm{~mm}, 2.2 \mu \mathrm{m}$, Thermo Scientific, USA). Because the negative mode gave a better 208 sensitivity, mass spectra were recorded in this ionization mode in full scan mode from 50 to $2091200 \mathrm{amu}$ at $2 \mathrm{~Hz}$. After the dataset normalization (Hashoum et al., 2017), around 6000 210 features were kept before the filtering steps were applied to ensure data quality and remove 211 redundant signals using an in-house script on $\mathrm{R}$ (Hashoum et al., 2017). At the end, 3030 ions 212 were kept for data analyses.

\subsection{Statistical analysis}


214 For all the chemical data, ANOVA were performed to test differences between two 215 interacting factors: Litter species (poplar, spruce, grass and mixture poplar-spruce) and litter 216 form (control, litter, 5\% leachate and 10\% leachate). Data were ln-transformed before 217 performing statistical tests if the conditions of normality and homoscedasticity of the residuals 218 were not met. After the analyses, multiple comparisons (Tukey contrasts) were done. To have 219 an estimation of the metabolomic diversity of each litter species, the Shannon diversity index 220 was calculated from all the metabolomic data including 3030 ions (Quinn et al., 2016; Ristok 221 et al., 2019). To detect compounds that were specific to each litter species we selected the 222 fifty most discriminating ions (Variable Importance in Projection, VIP) that differentiated the 223 three litter species using a PLS-DA analysis (Fig S1) with MetaboAnalystR (Chong and Xia, 224 2018). The features were annotated with constructor software (Bruker Compass DataAnalysis 225 5.0, Table S1). The most probable raw formulae and fragmentation patterns $\left(\mathrm{MS}^{2}\right.$ spectrum in negative mode) were compared with online databases (Metlin, Massbank of North America, 227 Pubchem using Metfrag, Table S1). Further, we constructed a heatmap with those VIPs to 228 visualise the relative intensities of each of these ions according to each litter type with R. A 229 binomial generalized linear model (GLM) was used to test the difference of collembolans 230 mortality rate in function of the different litter species (poplar, spruce, poplar/spruce mixture 231 and grass litters) and litter forms (control, litter, 5\% leachate and 10\% leachate). Binomial 232 GLMs are designed to fit proportions or percentages. A negative binomial GLM (i.e., a 233 specific version of a Poisson model that uses an additional parameter to correct for data over234 dispersion) with a log link function was used to test the difference in reproduction with the 235 different litter species (poplar, spruce, poplar/spruce mixture and grass litters) and litter forms 236 (control, litter, 5\% leachate and 10\% leachate). Negative binomial GLMs are designed to fit 237 count data (data that usually lacks normality), as it is generally the case when sampling 238 invertebrate taxa. All statistical analyses were done with R v.3.1.0 (R Core Team, 2017), 
using the package 'stats' for the ANOVA and binomial GLM and the package 'MASS' for the 240 negative binomial GLM.

\section{3. Results}

\subsection{Chemical composition of litters and leachates}

Spruce litter presented greater C concentrations, while grass litter had greater N concentrations compared to the two other litter types $(P<0.01$ and $\mathrm{P}<0.001$ respectively,

Table 1). Consequently, grass litter had the lowest and spruce litter the greatest $\mathrm{C} / \mathrm{N}$ ratios,

246 while poplar had intermediate values $(P<0.001)$. Phosphorus concentrations in the litters

247 were similar among the different litter species (Table 1). Concerning the total phenolics, grass

248 litter had more than four-fold lower phenolic concentrations compared to the three other litter

249 species $(P<0.001$, Fig. 1). For the soluble compounds, however, we observed that grass and

250 spruce leachates contained lower amounts of phenolic compounds compared to poplar and

251 mixed litters leachates $(P<0.005$, Fig. 1). The proportion of phenolics in the leachates

252 relative to the litters differed depending on the litter species; these proportions corresponded

253 to $36 \%, 7 \%, 31 \%$, and $38 \%$ of the total litter concentrations respectively for grass, spruce,

254 poplar-spruce mixture and poplar leachates (Fig. 1). Metabolomic diversity, calculated by the

255 Shannon index of the whole dataset, was lower in spruce and higher in poplar litters, with an

256 intermediate diversity in grass litter (ANOVA, $F=52.9, P<0.001$, Table 1). Qualitative

257 analysis of the 50 most discriminant features of the three litter species is reported in Fig. 2 and

258 shows that the majority of the features were specific to the poplar litter, and were present in

259 greater abundance than in the two other litter species. Among them, we identified caffeic acid

260 derivatives, pinocembrin and several pinocembrin derivatives, salicinin, quercetin and

261 arthromerin A (Table S1). Six features, among which we identified dehydroabietic acid, were

262 specific to the spruce litter, while rare or absent in the poplar litter. Three compounds were 
263 found either in the poplar and the grass litter, among them we identified chlorogenic acid and 264 ferulic acid (Table S1).

\subsection{Effects of litter and leachates on F. candida mortality}

266 Mortality of $F$. candida differed across combinations of litter species $\left(\mathrm{X}^{2}=63.1, P<0.001\right)$ 267 and forms $\left(\mathrm{X}^{2}=259.7, P<0.001\right)$ with a significant interaction term of the two factors $\left(\mathrm{X}^{2}=\right.$ $26857.5, P<0.001)$. While the mortality of $F$. candida with the grass litter or the $10 \%$ grass 269 leachate were similar to the mortality observed in the controls $(P>0.05$, Fig. 3$)$, a four-fold 270 increase in mortality was observed with the grass 5\% leachate compared to the control $(P<$ 271 0.001, Fig. 3). For the spruce litter, we observed an increase in mortality with all the litter 272 forms compared to the control (Fig. 3). With the litter itself, mortality reached 62\%, while it 273 reached $84 \%$ and $78 \%$ with the $5 \%$ and $10 \%$ leachates, respectively. Although the mortality 274 with the spruce litter leachates tended to be greater than with the litter, differences were only 275 marginally significant $(P=0.053$ and $P=0.058$ respectively). While the mortality of $F$. 276 candida with the mixed litter was similar to the mortality observed in the controls $(P>0.05$, 277 Fig. 3), a three-fold increase in mortality was observed with the 5\% leachate and the $10 \%$ 278 leachate compared to the litter, reaching mortality rates of $93 \%$ and $98 \%$, respectively $(P<$ 279 0.001, Fig. 3). Lastly, for the poplar litter, we observed an increase in mortality with all the 280 litter forms compared to the controls (Fig. 3). Mortality reached 68\% with the litter, while it 281 was $94 \%$ and $100 \%$ with the $5 \%$ and $10 \%$ leachates, respectively $(P<0.001$, Fig. 3$)$.

\subsection{Effects of litter and leachates on F. candida reproduction}

283 Reproduction of $F$. candida differed across combinations of litter species (negative Binomial 284 GLM, $\mathrm{X}^{2}=39.4, P<0.001$ ) and forms (Binomial GLM, $\mathrm{X}^{2}=70.5, P<0.001$ ) with a 285 significant interaction term (Binomial GLM, $\mathrm{X}^{2}=75.7, P<0.001$ ). Leachates of spruce, 286 mixed or poplar significantly reduced reproduction in comparison with the litter or the control 
treatments $(P<0.05$, Fig. 4). The grass litter and $10 \%$ leachate increased the reproduction of F. candida by $385 \%$ and $70 \%$, compared to the control, respectively. However, the grass $5 \%$ leachate decreased the reproduction by $83 \%$ compared to the control (Fig. 4).

\section{Discussion}

The aim of this study was to observe the fitness of $F$. candida in the presence of litter or leachates of different litter species with diverse chemical characteristics. We observed that leachates generally increased $F$. candida mortality compared to the litters. Additionally, we observed greater mortality rates of collembolans with tree leachates, which contained a greater quantity of phenolic compounds, compared to grass leachates. Our results also showed reproduction rates four times greater with grass litter than for tree litters or controls, in line with our previous in-situ litter decomposition study for which a greater abundance of organisms was observed when grass litter was added to spruce or poplar litter (Chomel et al., 2015a).

\subsection{Effects of litter species and its quality}

While we expected an increase of collembolans fitness with the presence of grass litter, we observed a considerable increase of their reproduction compared to the control and the other litter species, partially confirming our first hypothesis. Nutritional quality of decomposing litter depends on the chemical constituents of leaf tissues (Das and Joy, 2009; Heděnec et al., 2013). Grass litter had relatively low $\mathrm{C} / \mathrm{N}$ ratios and phenolic compounds contents, indicating greater concentrations of carbohydrates and proteins. This labile organic matter rich in $\mathrm{N}$ provides a readily available energy source to decomposers (Aber et al., 1990; Aerts, 1997), and induced better conditions for feeding and reproduction of collembolans (Das and Joy, 2009). While mortality rate with the grass litter was similar than the control, reproduction rate was much higher. This result confirms the benefit of "high" litter quality to enhance $F$. 
candida fecundity (Booth and Anderson, 1979; Scheu and Simmerling, 2004) and shorten the

312 period until oviposition starts (Scheu and Simmerling, 2004). Besides C/N ratios, litter 313 phenolic concentrations could also explain $F$. candida fitness. In comparison with the grass 314 litter, both poplar and spruce litters had more than four-fold greater concentrations of 315 phenolics. Within 'low' quality litters, poplar litter had lower $\mathrm{C} / \mathrm{N}$ ratios but similar total 316 phenolic concentrations than spruce litter, and both litter types negatively affected the survival 317 and reproduction of $F$. candida. We observed an increase in mortality of $240 \%$ and $210 \%$ 318 and a decrease in reproduction of $29 \%$ and $18 \%$, respectively for poplar and spruce litters, 319 compared to the control. We identified several specificities among the tree litter species: 320 spruce litter contained dehydroabietic acid, while pinocembrin and caffeic acid metabolites 321 were found in poplar litter. Pinocembrin is a flavonoid that has been recognized to have 322 antimicrobial activities (Rasul et al., 2013), and caffeic acid is also known to have strong 323 allelopathic and antimicrobial activities (Batish et al., 2008). The terpenoid dehydroabietic 324 acid is a defense metabolite abundant in resin, thus common in conifers (Phillips and Croteau, 325 1999). These three secondary metabolites potentially reduce the colonization of the litter by 326 microorganisms by their antimicrobial activities and can have repulsive effects on detritivores 327 (Chomel et al., 2016; Das and Joy, 2009). The presence of these secondary metabolites and 328 the high concentration of total phenolic compounds in tree litters compared to grass litter 329 could explain their strong and negative impact on $F$. candida survival and reproduction. 330 However, when these two species of litter were mixed, mortality rate was similar to the 331 control, confirming our fourth hypothesis. Mixed diets may significantly increase collembolan 332 fitness by providing a balanced nutrient intake from the different litters present in the mixture 333 or by a dilution of toxic compounds contained in one of the species (Hättenschwiler et al., 334 2005; Scheu and Simmerling, 2004). Conversely, although mixing the two litter types 
335 increased survival compared to single species litter, it had no effect on the reproduction of $F$. candida.

\subsection{Effects of leachates vs litter}

338 In agreement with our third hypothesis, leachates had a greater impact on $F$. candida fitness

339 compared to the litters. Some of the leached compounds can act as easily-available nutrient

340 sources for decomposers. However secondary metabolites can be toxic and can also have a 341 greater impact on organisms once released in the environment by leaching or decomposition 342 (Chomel et al., 2016). It appears that phenolic compounds from the poplar litter were more 343 water-soluble compared to those from spruce litter, as their leachates contained $38 \%$ of the 344 total phenolic compounds of the litter, while spruce leachates only contained $7 \%$ of the total 345 phenolic compounds of the spruce litter. This can be explained by the fact that needles have a thicker epidermis and hypodermis that reduce the leaching capacity of the inner leaf tissues 347 (Don and Kalbitz, 2005; Joly et al., 2016). Microcosms that received 10\% leachates of poplar, mixed poplar/spruce or spruce showed $100 \%, 94 \%$ and $78 \%$ of mortality, respectively, whereas grass leachates only induced $32 \%$ of mortality and was not different from the control,

350 indicating a strong influence of the compounds contained in the tree leaves on $F$. candida.

351 The greater diversity of poplar compounds and their higher solubility could explain why 352 poplar litter leachates induced stronger effects compared to spruce or grass litter leachates. This result is in line with our findings in a previous field experiment where we observed a lower abundance of soil fauna in poplar plantations compared to spruce or mixed plantations

355 (Chomel et al., 2015a). There is some evidence that soil microbial activity is highly dependent 356 on leachates. Indeed, soil respiration has been shown to be quickly responsive to litter 357 leachates input with a change in the soil microbial community (Cleveland et al., 2007; Joly et 358 al., 2016; Wieder et al., 2008) and soil respiration is significantly explained by the proportion 359 of water-soluble compounds contained in the leaf litter layer covering the soil (Fanin et al., 
2011). The differences in F. candida fitness observed with the different litter species could

361 also be an effect of the different microbial communities that are present in the leachates.

362 Several studies have shown that leachates can have strong allelopathic activity from one plant 363 species to another (Fernandez et al., 2013, 2006; Rice, 1984) and can have strong effects on 364 plant community diversity and composition (Ma et al., 2020); however, studies on the effect 365 of leachates on soil fauna communities are rare. Leaching of leaves and litter is an important 366 process in ecosystems since a large quantity of compounds can quickly be released by a 367 rainfall event, or gradually released during the litter decomposition process. Nonetheless, 368 litter leachates are rarely considered in studies on aboveground and belowground interactions, 369 whereas this study showed that they may contain bioavailable compounds that can be 370 significant drivers of collembolan fitness.

\section{5. Conclusion}

372 Litter species significantly affected $F$. candida mortality and reproduction. Grass litter 373 increased survival and reproduction of collembolans, while tree litters reduced survival. This 374 study also showed that leachates had greater impacts on collembolans fitness compared to 375 litter, with stronger negative effects of tree leachates compared to grass leachates. These 376 results indicate a strong influence of the compounds contained in the trees leaves. Phenolic 377 compounds in poplar leaves were more leachable than in spruce leaves and presented a 378 greater diversity, with the presence of several allelopathic compounds as caffeic acid and 379 pinocembrin, which could explain the stronger negative effect of poplar leachates. This study 380 showed that the release of compounds through leaching of leaves or litter could be an 381 important factor for the activity of soil organisms and for aboveground-belowground 382 interactions in natural ecosystems. Other studies should be conducted with more species of 383 collembola to see if similar patterns are observed. 


\section{Acknowledgements}

385 The authors thank to Thomas Tully (Ecole Normale Superieure, Paris, France) for providing 386 the initial culture of Folsomia candida. We thank Germain Boungou and Amélie Saunier 387 (IMBE) for the help with the phosphorus and metabolomic analyses. This work was supported 388 by the Natural Sciences and Engineering Research Council of Canada (NSERC-CRSNG, 389 grant number 381553-09). LC-MS analysis were conducted at the IMBE 'Chemical Ecology

390 and Metabolomics facility' funded by the CNRS, "Sud Provence-Alpes-Côte d'Azur" 391 regional council, TOTAL Foundation and the French National Research Agency (ANR).

\section{Declaration of interests}

393 The authors declare to have no competing interests that could have appeared to influence the 394 work reported in this paper 


\section{References}

396

397

398

399

400

401

402

403

404

405

406

407

408

409

410

411

412

413

414

415

416

417

418

419

420

421

422

423

424

425

426

Aber, J.D., Melillo, J.M., McClaugherty, C.A., 1990. Predicting long-term patterns of mass loss, nitrogen dynamics, and soil organic matter transformation from initial fine litter chemistry in temperate forest ecosystems. Canadian Journal of Botany 68, 2201-2208.

Aerts, R., 1997. Climate, leaf litter chemistry and leaf litter decomposition in terrestrial ecosystems: A triangular relationship. Oikos 79, 439-449.

Auclerc, A., Libourel, P.A., Salmon, S., Bels, V., Ponge, J.F., 2010. Assessment of movement patterns in Folsomia candida (Hexapoda: Collembola) in the presence of food. Soil Biology \& Biochemistry 42, 657-659. doi:10.1016/j.soilbio.2009.12.012

Batish, D.R., Singh, H.P., Kaur, S., Kohli, R.K., Yadav, S.S., 2008. Caffeic acid affects early growth, and morphogenetic response of hypocotyl cuttings of mung bean (Phaseolus aureus). Journal of Plant Physiology 165, 297-305. doi:10.1016/j.jplph.2007.05.003

Berg, B., McClaugherty, C., 2008. Plant litter decomposition, humus formation, carbon sequestration (2nd edition). Springer-Verlag, Berlin Heidelberg.

Booth, R.G., Anderson, J.M., 1979. The influence of fungal food quality on the growth and fecundity of folsomia candida (Collembola: Isotomidae). Oecologia 38, 317-323. doi:10.1007/bf00345191

Chen, F., Peng, S.L., Chen, B.M., Ni, G.Y., Liao, H.X., 2013. Allelopathic potential and volatile compounds of Rosmarinus officinalis L. against weeds. Allelopathy Journal $32,57-66$.

Chomel, M., DesRochers, A., Baldy, V., Larchevêque, M., Gauquelin, T., 2014. Non-additive effects of mixing hybrid poplar and white spruce on aboveground and soil carbon storage in boreal plantations. Forest Ecology and Management 328, 292-299. doi:10.1016/j.foreco.2014.05.048

Chomel, M., Guittonny-Larchevêque, M., DesRochers, A., Baldy, V., 2015a. Home Field Advantage of Litter Decomposition in Pure and Mixed Plantations Under Boreal Climate. Ecosystems 18, 1014-1028.

Chomel, M., Guittonny-Larchevêque, M., DesRochers, A., Baldy, V., 2015b. Effect of mixing herbaceous litter with tree litters on decomposition and $\mathrm{N}$ release in boreal plantations. Plant and Soil 1-13. doi:10.1007/s11104-015-2648-5

Chomel, M., Guittonny-Larchevêque, M., Fernandez, C., Gallet, C., DesRochers, A., Paré, D., Jackson, B.G., Baldy, V., 2016. Plant secondary metabolites: a key driver of litter 
decomposition and soil nutrient cycling. Journal of Ecology 104, 1527-1541. doi:10.1111/1365-2745.12644

Chong, J., Xia, J., 2018. MetaboAnalystR: an R package for flexible and reproducible analysis of metabolomics data. Bioinformatics 34, 4313-4314. doi:10.1093/bioinformatics/bty528

Christiansen, K.A., Bellinger, P., 1980. The Collembola of North America north of the Rio Grande. Part 2. Families Onychiuridae and Isotomidae. Grinnel College, Grinnel, IA.

Cleveland, C.C., Nemergut, D.R., Schmidt, S.K., Townsend, A.R., 2007. Increases in soil respiration following labile carbon additions linked to rapid shifts in soil microbial community composition. Biogeochemistry 82, 229-240. doi:10.1007/s10533-0069065-z

Das, S., Joy, V.C., 2009. Chemical quality impacts of tropical forest tree leaf litters on the growth and fecundity of soil Collembola. European Journal of Soil Biology 45, 448454. doi:10.1016/j.ejsobi.2009.09.001

Don, A., Kalbitz, K., 2005. Amounts and degradability of dissolved organic carbon from foliar litter at different decomposition stages. Soil Biology and Biochemistry 37, 2171-2179. doi:10.1016/j.soilbio.2005.03.019

Fanin, N., Hättenschwiler, S., Barantal, S., Schimann, H., Fromin, N., 2011. Does variability in litter quality determine soil microbial respiration in an Amazonian rainforest? Soil Biology and Biochemistry 43, 1014-1022. doi:10.1016/j.soilbio.2011.01.018

Fernandez, C., Lelong, B., Vila, B., Mévy, J., Robles, C., Greff, S., Dupouyet, S., BousquetMélou, A., 2006. Potential allelopathic effect of Pinus halepensis in the secondary succession: an experimental approach. Chemoecology 16, 97-105.

Fernandez, C., Santonja, M., Gros, R., Monnier, Y., Chomel, M., Baldy, V., Bousquet-Melou, A., 2013. Allelochemicals of Pinus halepensis as drivers of biodiversity in Mediterranean open mosaic habitats during the colonization stage of secondary succession. Journal of Chemical Ecology 39, 298-311. doi:10.1007/s10886-013-02396

Folin, O., Denis, W., 1915. A Colorimetric Method for the Determination of Phenols (and Phenol Derivatives) in Urine. Journal of Biological Chemistry 22, 305-308.

Fountain, M.T., Hopkin, S.P., 2005. Folsomia candida (Collembola): A "standard" soil arthropod. Annual Review of Entomology 50, 201-222. doi:10.1146/annurev.ento.50.071803.130331 
460

461

462

463

464

465

466

467

468

469

470

471

472

473

474

475

476

477

478

479

480

481

482

483

484

485

486

487

488

489

490

491

492

Gallet, C., Pellissier, F., 1997. Phenolic compounds in natural solutions of a coniferous forest. Journal of Chemical Ecology 24, 2401-2412. doi:10.1023/b:joec.0000006682.50061.83

Gartner, T.B., Cardon, Z.G., 2004. Decomposition dynamics in mixed-species leaf litter. Oikos 104, 230-246.

Gessner, M.O., Swan, C.M., Dang, C.K., McKie, B.G., Bardgett, R.D., Wall, D.H., Hattenschwiler, S., 2010. Diversity meets decomposition. Trends in Ecology \& Evolution 25, 372-380.

Hashoum, H., Santonja, M., Gauquelin, T., Saatkamp, A., Gavinet, J., Greff, S., Lecareux, C., Fernandez, C., Bousquet-Mélou, A., 2017. Biotic interactions in a Mediterranean oak forest: role of allelopathy along phenological development of woody species. European Journal of Forest Research 136, 699-710. doi:10.1007/s10342-017-1066-Z

Hättenschwiler, S., Bretscher, D., 2001. Isopod effects on decomposition of litter produced under elevated $\mathrm{CO} 2, \mathrm{~N}$ deposition and different soil types. Global Change Biology 7 , 565-579. doi:10.1046/j.1365-2486.2001.00402.x

Hättenschwiler, S., Tiunov, A., Scheu, S., 2005. Biodiversity and litter decomposition in terrestrial ecosystems. Annual Review of Ecology, Evolution, \& Systematics 36, 191218.

Hättenschwiler, S., Vitousek, P., 2000. The role of polyphenols in terrestrial ecosystem nutrient cycling. Trends in Ecology \& Evolution 15, 238-243.

Heděnec, P., Radochová, P., Nováková, A., Kaneda, S., Frouz, J., 2013. Grazing preference and utilization of soil fungi by Folsomia candida (Isotomidae:Collembola). European Journal of Soil Biology 55, 66-70. doi:10.1016/j.ejsobi.2012.12.005

Hopkin, S.P., 1997. Biology of the Springtails (Insecta: Collembola). Oxford University Press.

ISO 11267, 1999. Soil quality - inhibition of reproduction of Collembola (Folsomia candida) by soil pollutants. International Organization for Standardization, Geneva, Switzerland.

Joly, F.-X., Fromin, N., Kiikkilä, O., Hättenschwiler, S., 2016. Diversity of leaf litter leachates from temperate forest trees and its consequences for soil microbial activity. Biogeochemistry 129, 373-388. doi:10.1007/s 10533-016-0239-z

Joy, S., Joy, V.C., 1991. Food preference and growth rate of porcellio laevis reared on decomposing leaf litter. Entomon 16, 107-113. 
Kil, B.-S., 1992. Effect of pine allelochemicals on selected species in Korea, in: Rizvi, S.J.H., Rizvi, V. (Eds.), Allelopathy: Basic and Applied Aspects. Springer Netherlands, Dordrecht, pp. 205-241. doi:10.1007/978-94-011-2376-1_14

Klironomos, J.N., Bednarczuk, E.M., Neville, J., 1999. Reproductive significance of feeding on saprobic and arbuscular mycorrhizal fungi by the collembolan, Folsomia candida. Functional Ecology 13, 756-761. doi:10.1046/j.1365-2435.1999.00379.x

Klironomos, J.N., Widden, P., Deslandes, I., 1992. FEEDING PREFERENCES OF THE COLLEMBOLAN FOLSOMIA-CANDIDA IN RELATION TO MICROFUNGAL SUCCESSIONS ON DECAYING LITTER. Soil Biology \& Biochemistry 24, 685692. doi:10.1016/0038-0717(92)90047-2

Kuiters, A.T., 1990. Role of phenolic substances from decomposing forest litter in plant-soil interactions. Acta Botanica Neerlandica 39, 329-348.

Ma, Z., Wang, Y., Gu, Y., Bowatte, S., Zhou, Q., Hou, F., 2020. Effects of Litter Leachate on Plant Community Characteristics of Alpine Grassland in Qinghai Tibetan Plateau. Rangeland Ecology \& Management 73, 147-155. doi:10.1016/j.rama.2019.10.003

Marschner, B., Kalbitz, K., 2003. Controls of bioavailability and biodegradability of dissolved organic matter in soils. Geoderma, Ecological aspects of dissolved organic matter in soils 113, 211-235. doi:10.1016/S0016-7061(02)00362-2

Petersen, H., Luxton, M., 1982. A Comparative Analysis of Soil Fauna Populations and Their Role in Decomposition Processes. Oikos 39, 288-388. doi:10.2307/3544689

Phillips, M.A., Croteau, R.B., 1999. Resin-based defenses in conifers. Trends in Plant Science 4, 184-190. doi:10.1016/S1360-1385(99)01401-6

Poinsot-Balaguer, N., Racon, L., Sadaka, N., Lepetit, J., 1993. Effects of tannin compounds on two species of Collembola. European Journal of Soil Biology 29, 13-16.

Quinn, R.A., Vermeij, M.J.A., Hartmann, A.C., Galtier d'Auriac, I., Benler, S., Haas, A., Quistad, S.D., Lim, Y.W., Little, M., Sandin, S., Smith, J.E., Dorrestein, P.C., Rohwer, F., 2016. Metabolomics of reef benthic interactions reveals a bioactive lipid involved in coral defence. Proceedings of the Royal Society B: Biological Sciences 283, 20160469. doi:10.1098/rspb.2016.0469

R Core Team, 2017. R: A language and environment for statistical computing. R Foundation for Statistical Computing, Vienna, Austria. URL http://www.R-project.org.

Rasul, A., Millimouno, F.M., Ali Eltayb, W., Ali, M., Li, J., Li, X., 2013. Pinocembrin: A Novel Natural Compound with Versatile Pharmacological and Biological Activities 
[WWW Document]. BioMed Research International. doi:https://doi.org/10.1155/2013/379850

Rice, E.L., 1984. Allelopathy. Academic Press, Londres.

Rief, A., Knapp, B.A., Seeber, J., 2012. Palatability of selected alpine plant litters for the decomposer Lumbricus rubellus (Lumbricidae). Plos One 7, 7. doi:10.1371/journal.pone.0045345

Ristok, C., Poeschl, Y., Dudenhöffer, J.-H., Ebeling, A., Eisenhauer, N., Vergara, F., Wagg, C., Dam, N.M. van, Weinhold, A., 2019. Plant species richness elicits changes in the metabolome of grassland species via soil biotic legacy. Journal of Ecology 107, 2240 2254. doi:10.1111/1365-2745.13185

Salmon, S., Ponge, J.F., 2001. Earthworm excreta attract soil springtails: laboratory experiments on Heteromurus nitidus (Collembola : Entomobryidae). Soil Biology \& Biochemistry 33, 1959-1969. doi:10.1016/s0038-0717(01)00129-8

Skidmore, R.E., 1995. Checklist of Collembola (Insecta: Apterygota) of Canada and Alaska. Proc. Ent. Soc. Ontario 126, 45-76.

544 Vyvyan, J.R., 2002. Allelochemicals as leads for new herbicides and agrochemicals. Tetrahedron 58, 1631-1646. doi:10.1016/S0040-4020(02)00052-2

546 Wieder, W.R., Cleveland, C.C., Townsend, A.R., 2008. Tropical tree species composition affects the oxidation of dissolved organic matter from litter. Biogeochemistry 88, $127-$ 138. doi:10.1007/s10533-008-9200-0

Zheng, J., Xu, Z., Wang, Y., Dong, H., Chen, C., Han, S., 2014. Non-additive effects of mixing different sources of dissolved organic matter on its biodegradation. Soil 


\section{Figure captions}

555 Figure 1. Total phenolic concentration of litters (white bars) and 10\% leachate (black bars)

556 expressed in gallic acid equivalent. Mean \pm SE.

557 Figure 2. Heatmap of the fifty most discriminant ions (Variable Importance in Projection, 558 VIP) from the LC-MS metabolomic fingerprints of the three litter species. These 50 ions are 559 the discriminatory compounds between the three species. The colour in the heatmap indicates $560 \log$ transformed ratio of a given ion $v s$ the average intensity of the ions in all samples. 561 Negative and positive values are coded with blue and red colours, respectively, and they 562 indicate under- or over-expression of the specific feature in one species compared to the 563 others.

564 Figure 3. Mortality of Folsomia candida (mean \pm SE) growing in mesocosms with the 565 different litter species (grass, spruce, mixture poplar/spruce, poplar) and forms (control, litter, $5665 \%$ leachates and 10\% leachates). Different letters denote significant differences according to 567 Tukey contrasts.

568 Figure 4. Reproduction of Folsomia candida (mean $\pm \mathrm{SE}$ ) growing in mesocosms with the 569 different litter species (grass, spruce, mixture poplar/spruce, poplar) and forms (control, litter, $5705 \%$ leachates and $10 \%$ leachates). Different letters denote significant differences according to 571 Tukey contrasts. 
576 Table 1. Initial concentrations of $\mathrm{C}$ and $\mathrm{N}, \mathrm{C} / \mathrm{N}$ ratio, $\mathrm{P}$ and metabolomic diversity of the 577 different litter types (mean $\pm \mathrm{SE})$.

\begin{tabular}{lcccc}
\hline & \multicolumn{3}{c}{ Litter species } & F value \\
\cline { 2 - 5 } & Poplar & Spruce & Grass & \\
\hline $\mathrm{C}(\% \mathrm{DM})$ & $38.1 \pm 1.2(\mathrm{a})$ & $42.3 \pm 1.5(\mathrm{~b})$ & $36.9 \pm 1.1(\mathrm{a})$ & $5.1 * *$ \\
$\mathrm{~N}(\% \mathrm{DM})$ & $0.5 \pm 0.02(\mathrm{a})$ & $0.5 \pm 0.02(\mathrm{a})$ & $0.65 \pm 0.03(\mathrm{~b})$ & $14.9 * * *$ \\
$\mathrm{C} / \mathrm{N}$ & $76.7 \pm 4(\mathrm{~b})$ & $86.7 \pm 3.5(\mathrm{c})$ & $58.9 \pm 2.2(\mathrm{a})$ & $20.6 * * *$ \\
$\mathrm{P}\left(\mathrm{mg} \mathrm{g}^{-1} \mathrm{DM}\right)$ & $0.49 \pm 0.01$ & $0.53 \pm 0$ & $0.48 \pm 0.01$ & $2.3 \mathrm{~ns}$ \\
Metabolomic diversity & $3.03 \pm 0.10(\mathrm{c})$ & $1.06 \pm 0.12(\mathrm{a})$ & $1.88 \pm 0.18(\mathrm{~b})$ & $52.9 * * *$ \\
\hline
\end{tabular}

578 Results of ANOVAs are reported on the right side, with significant differences indicated with ${ }^{*} 0.05, * * 0.01$,

$579 * * * 0.001$. Different letters within a row denote significant differences according to Tukey tests $(\mathrm{a}<\mathrm{b}<\mathrm{c}$ with 0.05

580 significance threshold) 


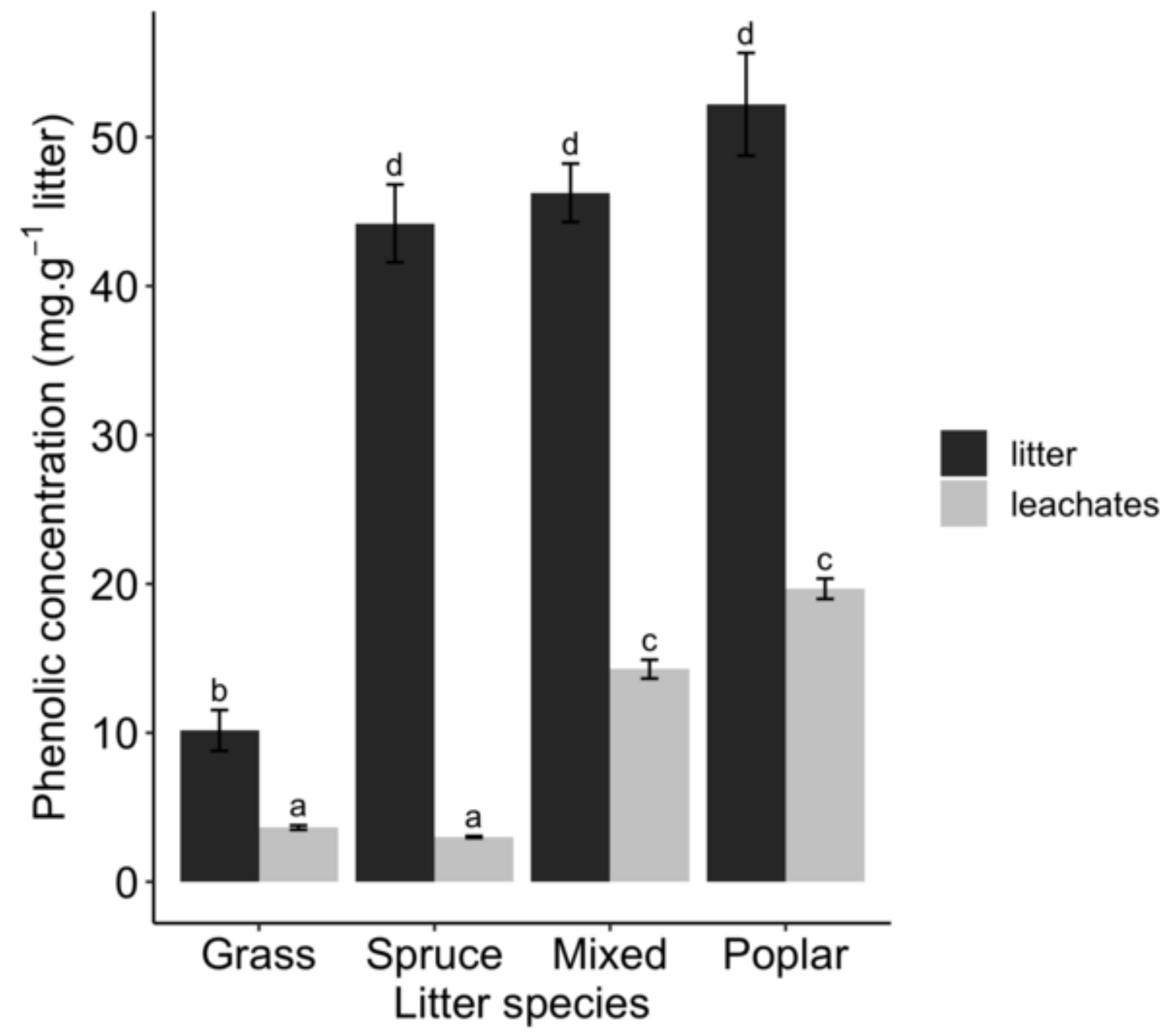

litter leachates 
Click here to download high resolution image

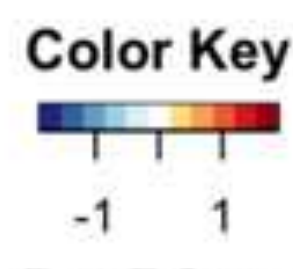

Row Z-Score

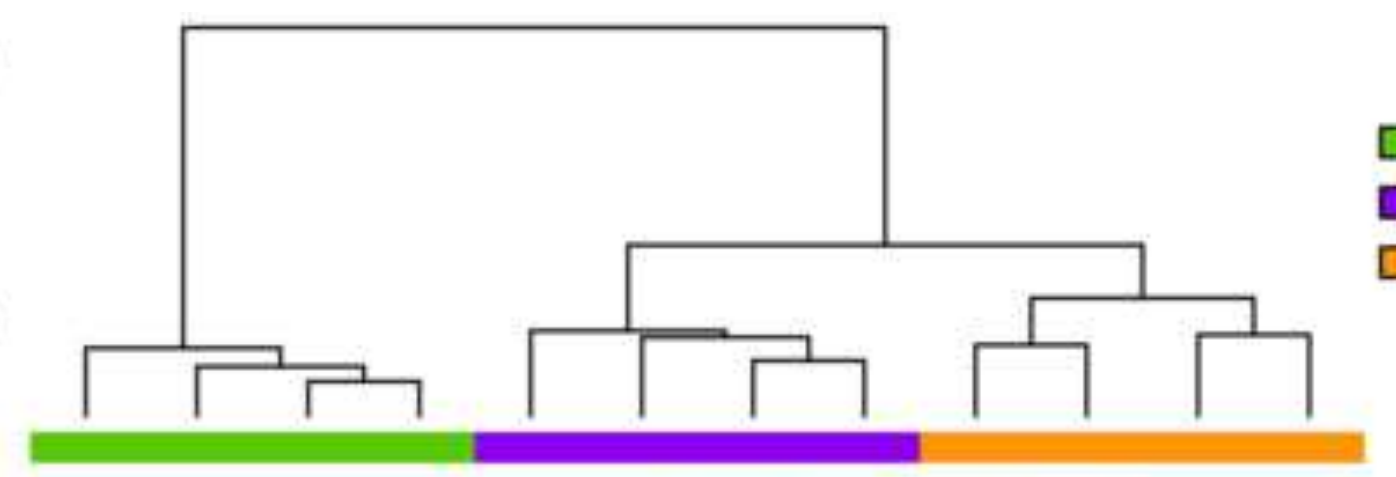

$\square$ Poplar

- Spruce

$\square$ Grass
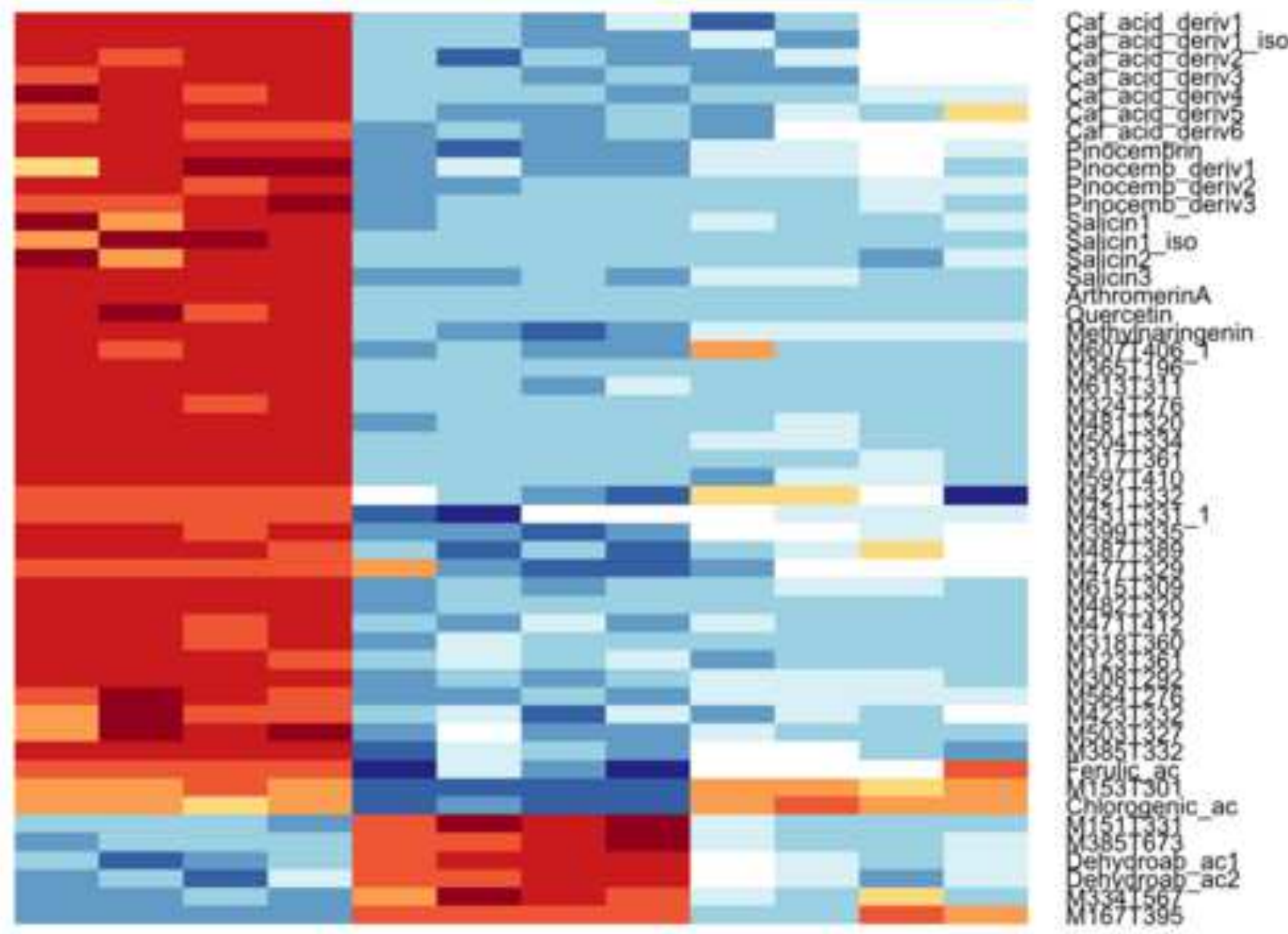

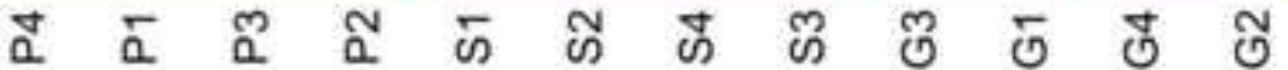




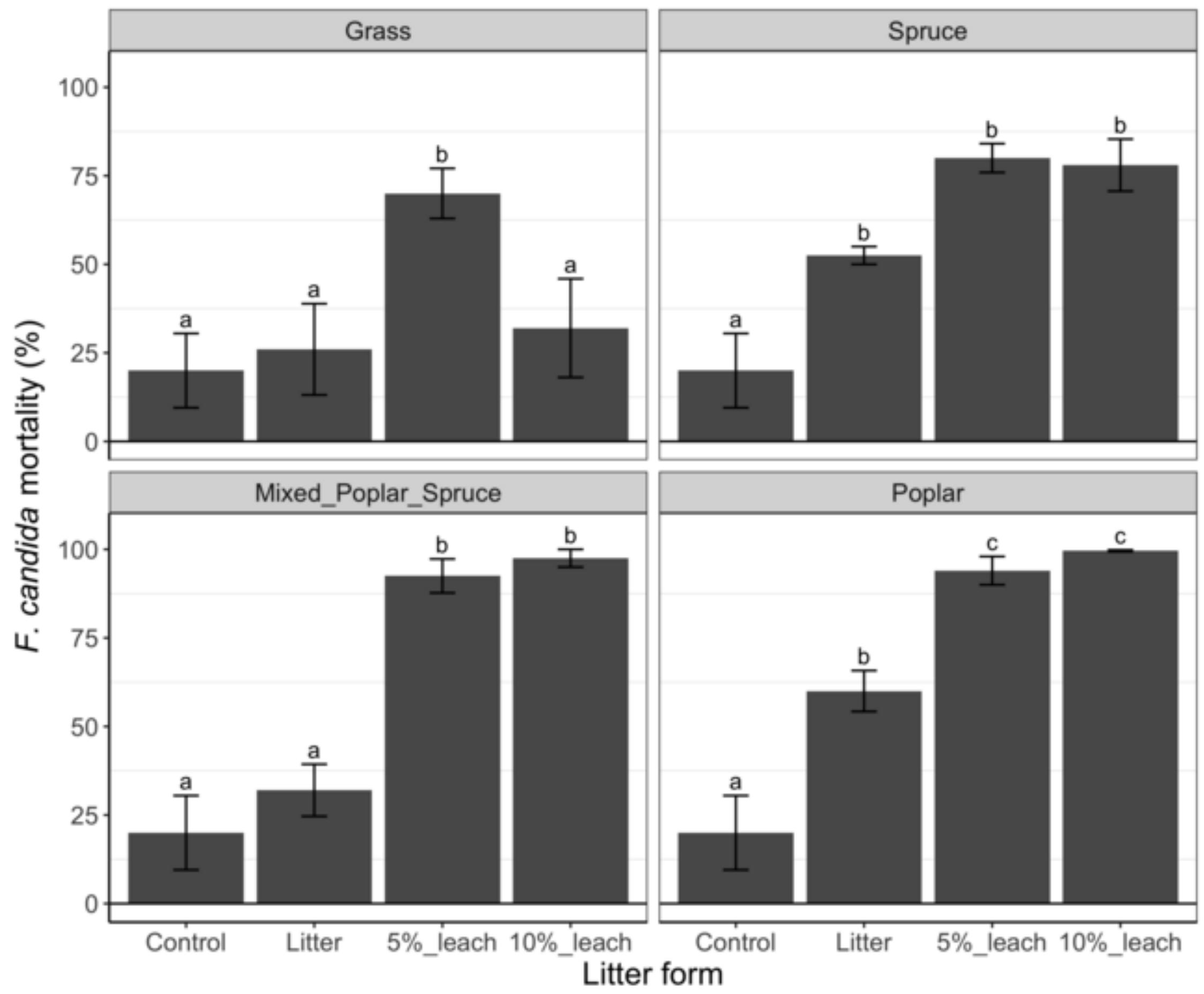




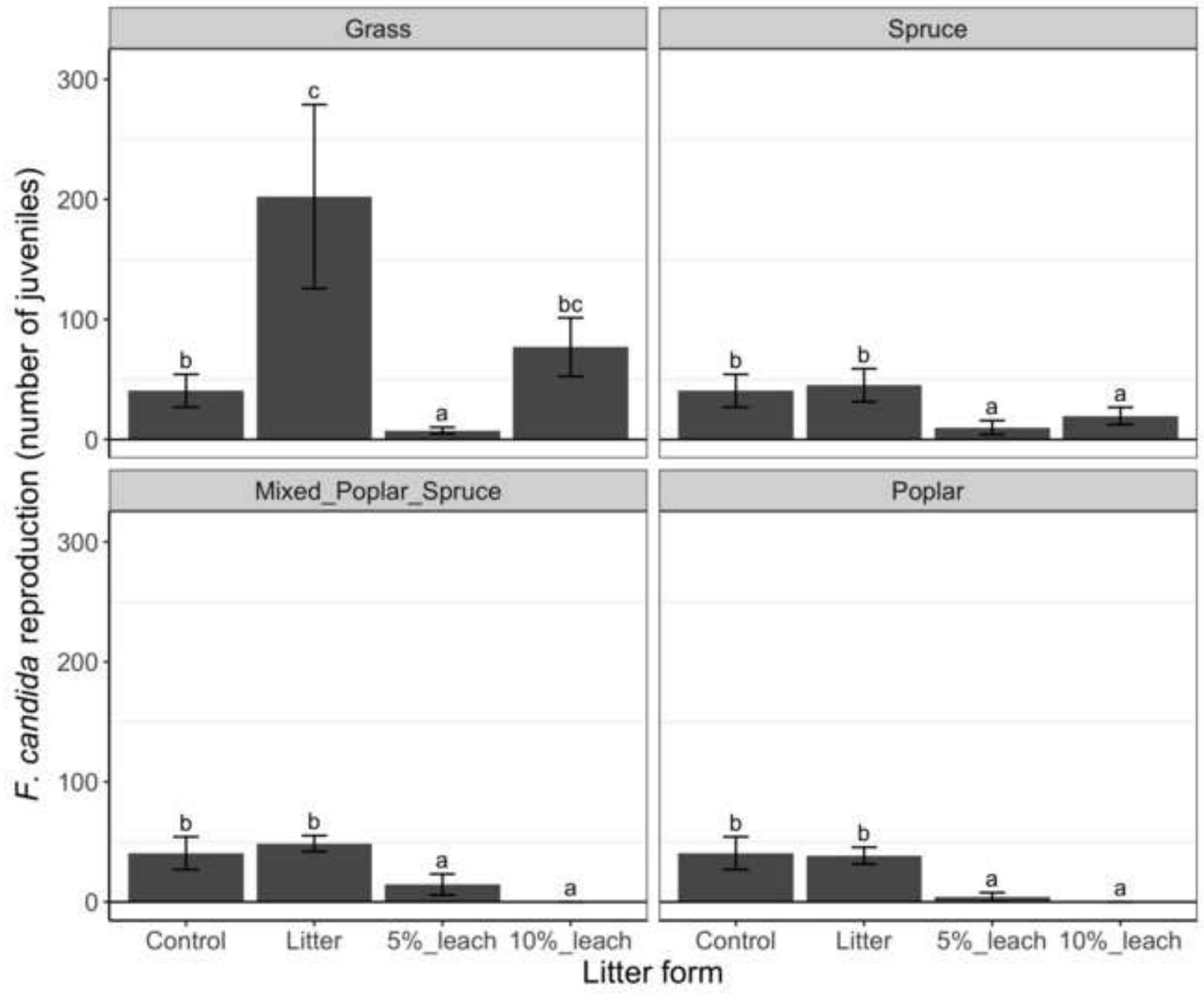


Supplementary Material

Click here to download Supplementary Material for online publication only: Supplementary Material.docx

che

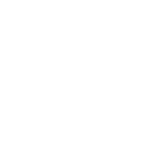

(1)

(1)

(1)

(1)

(1)

.

.

.

.

.

.

.

.

.

.

.

.

.

.

.

.

.

.

.

.

.

.

.

.

.

.

.

. 